\title{
CNC Freze tezgahları için bir program arayüzünün tasarlanması
}

\section{Designing a program interface for $\mathrm{CNC}$ milling machines}

\author{
Mikail Olam ${ }^{1, *(D)}$, Nihat Tosun² \\ ${ }^{1,2}$ Fırat Üniversitesi, Mühendislik Fakültesi, Makine Mühendisliği Bölümü, Elâzığ, Türkiye
}

\begin{abstract}
Özet
$\mathrm{Bu}$ çalışmada, mobilya endüstrisinde kullanılan CNC freze tezgâhları için Visual Basic programlama dili kullanılarak bir program arayüzü tasarlanmıştır. Hazırlanan program arayüzü ile CNC freze tezgâhı arasında PCI hareket kontrol kartı kullanıldı. $\mathrm{Bu}$ program arayüzünün ergonomik tasarımı sayesinde, kullanıcılar CNC tezgahlarında kullanılan $\mathrm{G}$ ve $\mathrm{M}$ kodlarına ihtiyaç duymadan rahatlıkla kullanabilecektir. Yapılan çalışmada, program arayüzü resim formatlarındaki iki boyutlu şekilleri başarılı bir şekilde vektörel çizime dönüştürerek takım yollarını oluşturmaktadır. Vektörel çizimler program arayüzünde txt, bmp, png, jpeg, tiff, emf ve gif resim formatlarında dişa ve içe aktarma işlemleri doğru bir şekilde gerçekleştirilmektedir. Program arayüzünde bulunan başlık çubuğu, menü çubuğu, anlık durum göstergesi, şekil oluşturma alanı, hızlı erişim düğmeleri, koordinat listesi, cep boşaltma, işlem ayarı, çoklu işlem ve resim ayarı penceresi araçları için hazırlanan metotların işlevleri doğru bir şekilde yaptığg 1 görüldü.
\end{abstract}

Anahtar kelimeler: CNC, program arayüzü, Visual basic, Hareket kontrol kartı

\section{Giriş}

Hassas ve verimli işleme yanında kolay kullanım sağlayan bilgisayarlı sayısal kontrol (CNC) gelişmiş bir üretim teknolojisidir [1, 2]. Endüstriyel makinelerin beyni olan bilgisayar sayısal kontrol, modern bir imalat sisteminin temel unsurudur [3, 4]. CNC tezgâhları, imalat resminde ön görülen şekil ve boyutlarda bitmiş parça imal etmek için kullanılmaktadır [5]. Takım tezgâhlarının amacı, hammaddeye toleranslarla belirtilen bir kalitede şekil vermektir. Şekil verme işlemi, takım ve parçanın izafi hareketleri sonucu olarak talaş kaldırma ile gerçekleşir [6]. CNC tezgâhlarında programla belirtilen bu hareketler, tezgâhın kontrol ünitesi tarafından vurgu şeklinde elektronik sinyallere dönüştürür [7]. Bu sinyaller motoru ve buna bağlı mekanik iletim sistemi (dişli çark, civata mekanizması vb.) ile bağlı olan kızağı harekete geçirerek sağlar. Bütün bu hareketli tezgâh parçalarının kullanıcı tarafından bilgisayar destekli kontrolleri program arayüzleri kullanılarak yapılmaktadır. Bu program arayüzleri, CNC tezgahlarında bulunan motorlara ait sürücü devreleri ve tezgâh parçalarının durum bilgisini veren sensörlerden gelen verinin bilgisayar tarafından işleyip/yorumlayan paket programlardır [8]. Program arayüzleri tarafından CNC tezgahlara iletilen/alınan

\begin{abstract}
In this study, a new program interface has been designed using the visual basic programming language for $\mathrm{CNC}$ milling machines used in the furniture industry. PCI motion control card was used between the prepared program interface and the CNC milling machine. Thanks to the ergonomic design of this program interface, users can easily use them without the need for $\mathrm{G}$ and $\mathrm{M}$ codes used on CNC machines. As a result of the work done; It was seen that toolpaths were created by successfully converting twodimensional shapes in picture formats into vectorial drawing. It correctly performs the function of exporting and importing vectorial drawings into the program interface in txt, bmp, png, jpeg, tiff, emf and gif image formats. It was seen that the methods prepared for the title bar, menu bar, instant status indicator, shape creation area, quick access buttons, coordinate list, pocket emptying, process setting, multi-process and picture setting window tools in the program interface function properly.
\end{abstract}

Keywords: Program interface, Visual basic, CNC, Motion control card

komutları elektriksel sinyallerine dönüşümünü elektronik kartlar (haberleşme kartı) sağlamaktadır. Haberleşme kartları program arayüzü tarafında gönderilen komutları $G$ ve $\mathrm{M}$ kod formatına dönüştürüp motor sürücülerine ileten programlanmış devre kartlarıdır $[9,10]$. Bu haberleşme kartları bilgisayardaki ISA, PCI (Peripheral Component Interconnect), COM, LPT, USB, ethernet gibi portlarını kullanarak iç/dış aygıtlar ile veri iletimini sağlar [11-13]. Veri yolları verileri çok kanaldan çoklu bitler (kelimeler) seklinde ileten paralel veri yolu ya da tek kanal üzerinden bit bit ileten seri veri yolu biçimindedir [14]. PCI günümüz masaüstü bilgisayarlarında kullanılan en yüksek performansa sahip yol sistemidir [15]. PCI veri yolları, takçalıştır özellikli 32/64 bit paralel veri yolunu kullanmaktadır [16]. Günümüz bilgisayarlarında 2019 yılında PCI veri yolunun geliştirilen en son versiyonu olan PCIe 5.0 ile $128 \mathrm{~GB} / \mathrm{s}$ bant genişliğinde $32 \mathrm{GT} / \mathrm{s}$ bağlantı hızıyla veri aktarımı yapmaktadır [17]. PCI slotları LAN, SCSI, USB ve diğer kartları desteklemektedir. Günümüzde PCI veri yollarını kullanan birçok hareket kontrol kartları vardır. $\mathrm{Bu}$ kontrol kartlarının birbirleriyle temel farkları giriş/çıkış pin sayısı, çalışma frekansları, kullandıkları veri uzunlukları (32/64 bit), kontrol ettikleri motor sayısı ve destekledikleri

\footnotetext{
* Sorumlu yazar / Corresponding author, e-posta / e-mail: mikailolam@gmail.com (M.Olam)

Geliş / Recieved: 15.06.2021 Kabul / Accepted: 11.08.2021 Yayımlanma/Published: 14.01.2022

doi: 10.28948 /ngmuh. 952757
} 
enterpolasyon tipleri (doğrusal, dairesel, sürekli) gibi özelliklerdir [18, 19]. Ancak bu kontrol kartlarının birçoğu açık kaynak kodlu olarak sunulmamaktadır. Açık kaynak kodlu yazilımlar kullanici tarafindan değiştirilebilen/geliştirilebilen yazılımlardır $[20,21]$. Günümüzde CNC tezgahlar için bilgisayarlarda ticari olarak sunulan birçok program arayüzü (mach3, Haidenhain, Fidia, Siemens, vb.) vardır [22, 23]. Ticari ürün olarak sunulan CNC program arayüzlerinin kullanıcı tarafindan geliştirilmesi ya da değiştirilmesine izin verilmemektedir.

$\mathrm{Bu}$ çalışmada, bilgisayarın PCI portunu kullanan açık kaynak hareket kontrol kartı (motion control) kullanılarak mobilya endüstrisinde kullanılacak ergonomik kullanıma sahip bir CNC program arayüzü geliştirildi.

\section{Deneysel metot}

Bu çalışmada, visual basic programlama dili kullanılarak mobilya endüstrisinde kullanılan CNC freze tezgâhlar için bir programlama arayüzü tasarlanmıştır. Tasarlanan program arayüzü ile CNC tezgâh arasında PCI yuvasina takılan adtech marka ADT 8948A1 hareket kontrol kartı (Tablo 1) kullanılarak haberleşme sağlanmıștır. Şekil 1'de görüldüğü üzere ADT 8948A1 hareket kontrol kartı program arayüzü ile CNC freze tezgahının arasında köprü görevi görmektedir. Program arayüzü tarafından tezgâha gönderilen/alınan komutlar kontrol kartı üzerinden ilgili motorların sürücülerine iletilir ya da alınır. Program arayüzünde oluşturulan bir iş parçanın $\mathrm{x}, \mathrm{y}$ ve $\mathrm{z}$ eksen hareket koordinatlarını CNC freze tezgâhına işlenmek üzere gönderilir. CNC freze tezgâhının üç ekseninde bulunan servo motorlar, program arayüzü tarafindan gelen koordinatlara uygun olarak hareket etmesiyle kesme/işleme işlemi gerçekleşir.

Tablo 1. ADT 8948A1 hareket kontrol kartı (ADT 8948A1 motion control card)

\begin{tabular}{ll}
\hline Veri işlem uzunluğu & 32 bit \\
Dijital giriş sayısı & 32 (5-24VDC) \\
Dijital çıkış sayısı & 32 (5-24VDC NPN) \\
Encoder girişi & 4 eksen 32 bit \\
İnterpolasyon & 3 eksen (lineer) doğrusal, 2 \\
eksen dairesel, sürekli & 4 MHz \\
Çıkış çalışma frekansı & Var \\
Hareket halinde hız ve pozisyon & Var \\
değişimi & Var \\
Pulse/Dir ve Up/Down tipi pulse & Var \\
Harici sinyal ile hareketi başlatıp & Builder, Labview, Delphi ve \\
durdurma & Visual Basic \\
Desteklediği kart sayısı &
\end{tabular}

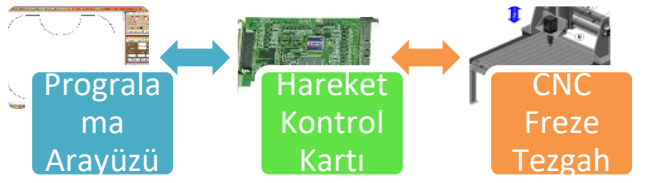

Şekil 1. Sistem çalışma şeması

Program arayüzünde iş parçasının çizimi üç yöntem ile oluşturulabilmektir. Birinci yöntem, kâğıt ya da düz temiz bir zemin üzerine iki boyutlu teknik resmin çizgileri üzerinde Şekil 2a'da gösterildiği gibi kablosuz kalem fare dolaştırılır. Farenin $\mathrm{x}$ ve y yönündeki her piksel hareketi $\mathrm{x}$ ve $\mathrm{y}$ koordinatları olarak program arayüzüne anlık olarak aktarılır (Şekil 2b). İkincisi yöntem, iki boyutlu çizim yapan programlar (paint, fireworks, photoshop, vb.) ile oluşturulan bitmap formatlı (JPEG, PNG, TIFF, vb.) iş parçası çizimi program arayüzüne import edilir. Çizimin $x$ ve $y$ koordinatları program arayüzü oluşturulan algoritma tarafından algılanarak vektörel çizime dönüştürülmesi işlemidir. Birinci ve ikinci yöntem ile program arayüzünde oluşturulan $\mathrm{x}$ ve y koordinatlarına $\mathrm{z}$ koordinatı da ilave edilerek çizime ait takım yolu elde edilir. Üçüncü yöntem de ticari olarak kullanılan program arayüzleri gibi işlenecek iş parçasını oluşturan X, Y ve Z eksen koordinatlarının manuel olarak girilmesidir. $\mathrm{Bu}$ üç eksene ait takım yolu koordinatları, bilgisayarın PCI yuvasına takılan hareket kontrol kartı sayesinde tezgâhın $\mathrm{x}, \mathrm{y}$ ve $\mathrm{z}$ eksenlerinde bulanan servo motorlara iletilir. Böylece bu iş parçası üzerinden kesici takımın üç boyutlu koordinatlara uygun bir biçimde hareket etmesi sağlanarak işleme/kesme işlemi gerçekleştirilir.

\section{Sonuçlar ve tartışmalar}

Program arayüzü Microsoft Visual Studio editöründeki Basic programlama dili kullanılarak hazırlanmıştır. Program arayüzü Şekil 3’te görüldüğü üzere, başlık çubuğu, menü çubuğu, anlık durum göstergesi, şekil oluşturma alanı, hızlı erişim düğmeleri, koordinat listesi, cep boşaltma, işlem ayarı, çoklu işlem ve resim ayarı penceresi bölümlerinden oluşmaktadır.

Başlık çubuğu, Şekil 4'te üzerinde gösterilen kontrollerden oluşmaktadır. Bu kontrollerin click olayına Şekil 4'de gösterilen komut satırları yazılarak çalışma ekranını simge durumuna küçültme ve çalışma ekranını kapatma işlevi gerçekleştirildi. Başlık çubuğunda aynı zamanda aktif olan çalışma adı ve yolu eklenen Label etiketi kullanılarak gösterildi

Menü çubukları Microsoft Visual Studio editörünün "Menüler ve Araç Çubukları" penceresindeki MenuStrip bileșeni kullanılarak Şekil 5'te gösterilen menüler oluşturulmuştur. Vektörel çizim ve bitmap çizimleri için PictureBox nesneleri kullanılmıştır. Program arayüzünde, Geri ve İleri alma işlemin yapılan her işlem 3 boyutlu dizi değiş̧enlerinde saklanmıştır. Geri alma işleminde Şekil 6'da gösterilen akış diyagramına göre metot yazılmış ve uygulanmıştır.

İleri alma işlemi de Geri alma işleminin akış diyagramına benzer şekilde uyguland 1 ve doğru bir şekilde işlev yaptı̆̆ görüldü. Şekil oluşturma alanındaki PictureBox nesnesi üzerine çizilen çizimin Ayarlar menüsündeki 
Büyütme/Küçültme seçeneğini girilen oran doğrultusunda yapmaktadır. Şekil büyütme işleminde çizimi oluşturan $X$ ve Y koordinatları büyütme/küçültme oranı çarpıldı, küçültme işleminde ise büyütme/küçültme oranına bölünerek yeni çizim koordinatları bulunarak şekil yeniden çizilmiştir.
Düzen menüsündeki Şekli Alana Sı̆̆dır seçeneği, çizimi oluşturan $\mathrm{X}$ ve $\mathrm{Y}$ koordinatların içerisindeki minimum ve maksimum $\mathrm{X}$ ve $\mathrm{Y}$ koordinat değerleri göre büyütme/küçültme işlemi uygulanarak gerçekleştiril

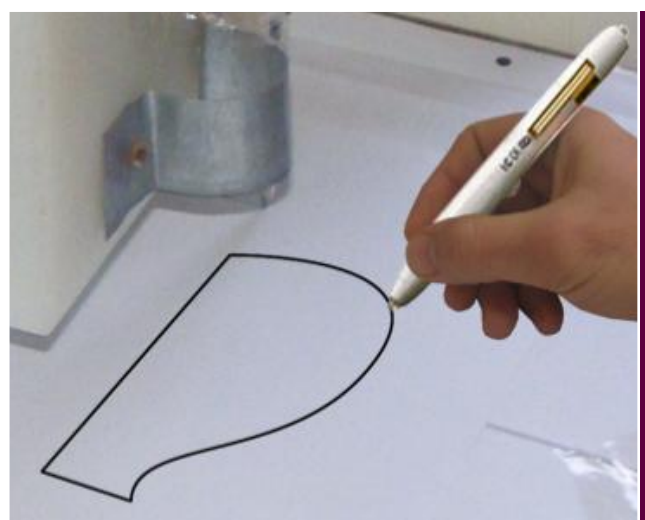

a)

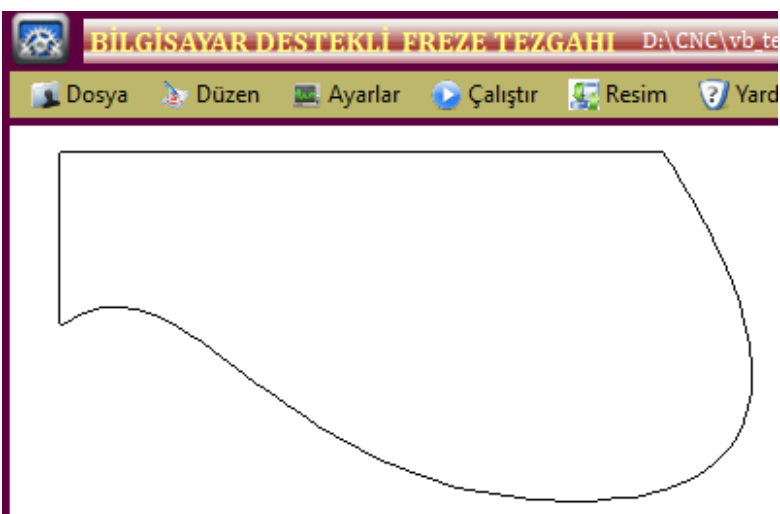

b)

Şekil 2. İki boyutlu çizimin program arayüzüne aktarılması

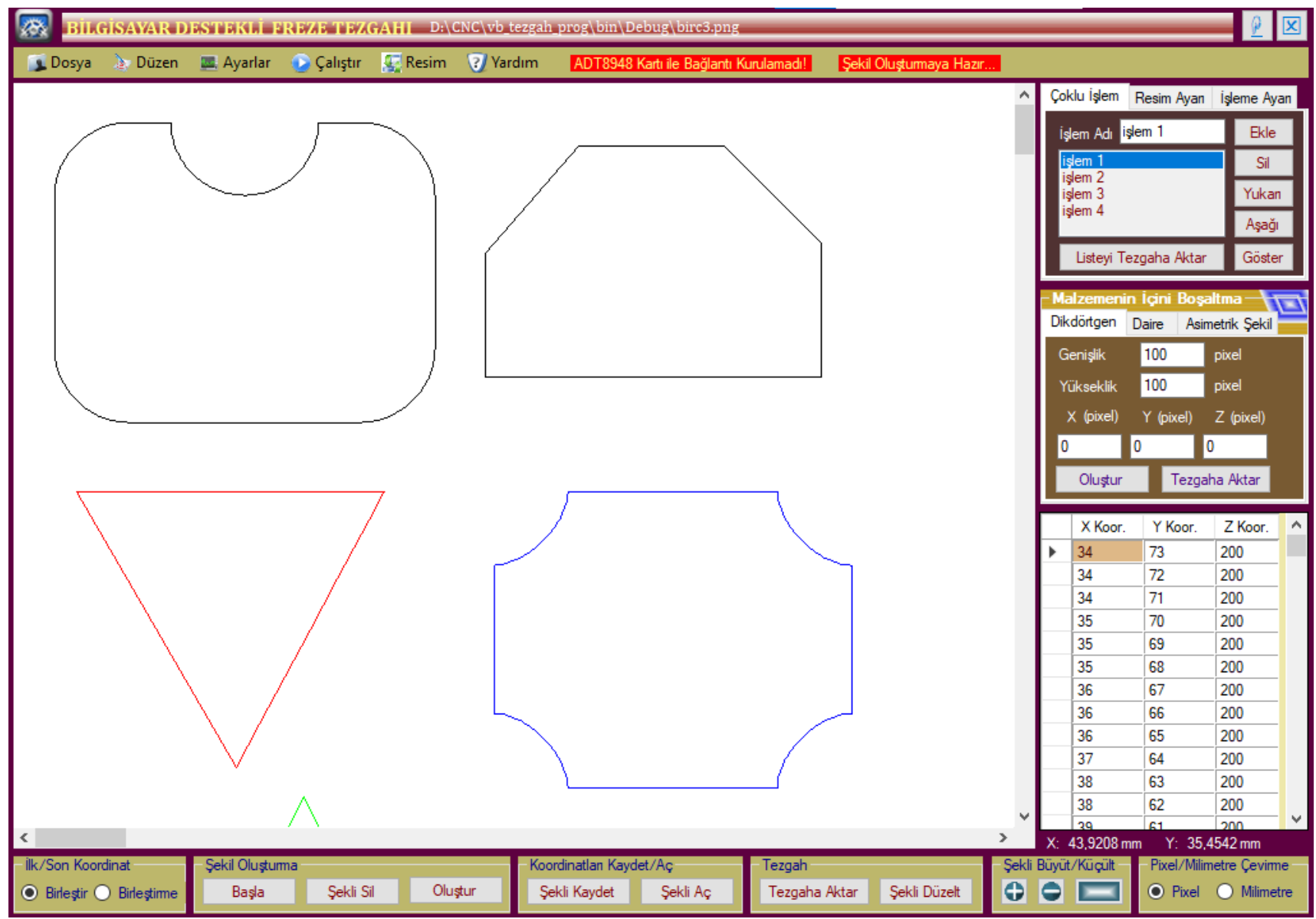

Şekil 3. CNC freze tezgahının program arayüzü

Form1.ActiveForm.Close() (Program arayüzünü kapat) Me. WindowState $=$ FormWindowState. Minimized (Simge durumuna küçült)

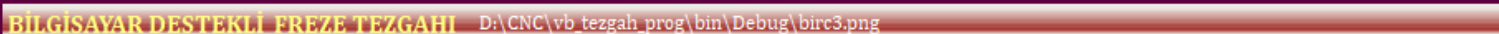

Şekil 4. Başlik çubuğu 


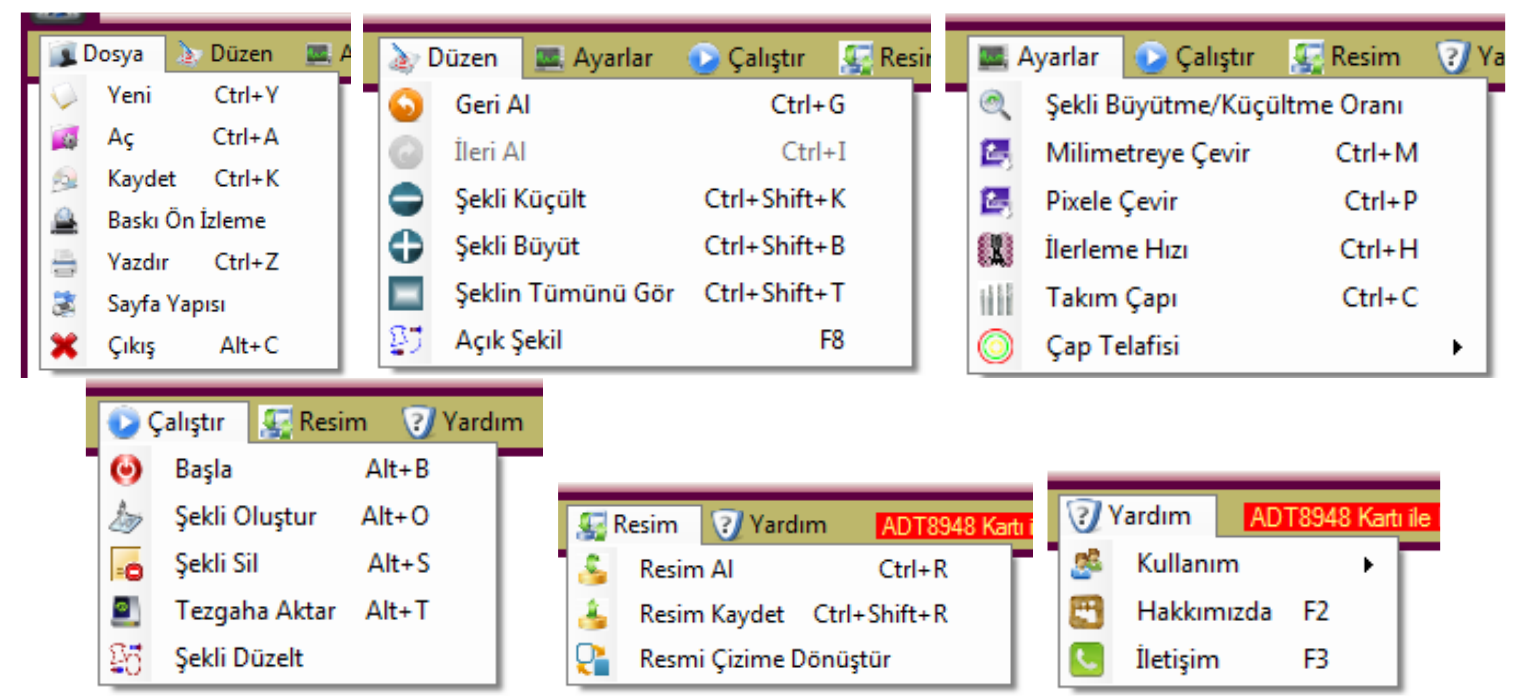

Şekil 5. Menü çubuğu

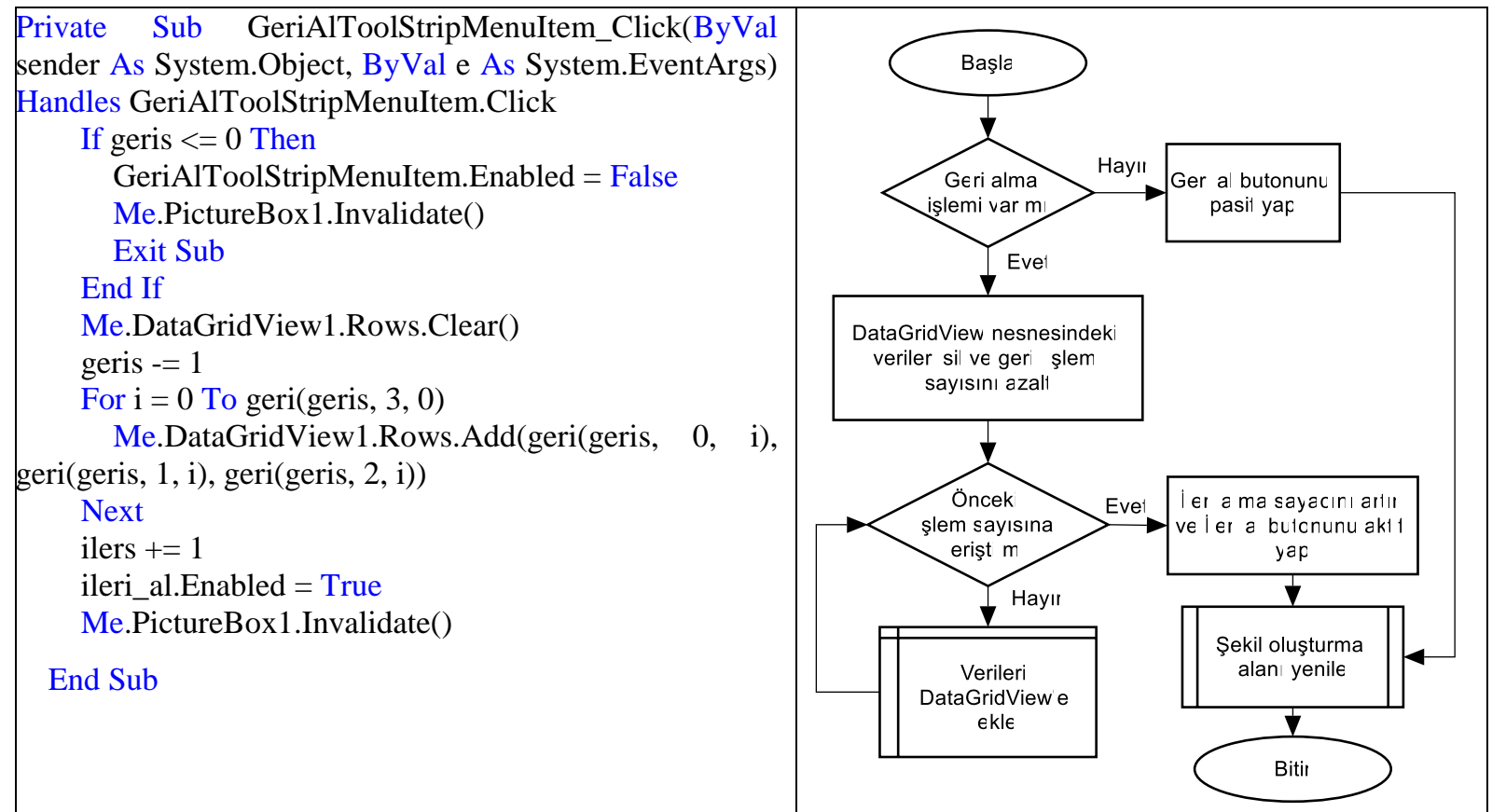

Şekil 6. Geri alma işleminde hazırlanan komutsal yapısı(sol taraf) ve akış diyagramı (sağ taraf)

Düzen menüsündeki Açık Şekil seçeneği, şekil oluşturma alanında yapılan çizimin başlangıç bitiş noktalarının kapalı/açık olacağını belirtmektedir (Şekil 7). Ayarla menüsünde şekli Büyütme/Küçültme Oranı seçeneğinde şekil oluşturma alanındaki şeklin büyütme /küçültme oranını ayarlar. Ayarla menüsünde Milimetreye Çevir ve Pixele Çevir seçenekleri, koordinat listesi kısmındaki koordinatların pixel/mm birimine dönüștürerek şekli yeniden oluşturur. Dönüştürme işlemi bilgisayarın o anki DPI (bir inch uzunluğu üzerindeki piksel sayısı) değeri baz alınarak yapılmıştır. Ayarlar menüsündeki İşleme Hızı, malzeme işlenirken ilerleme hızını ayarlar. Ayarlar menüsündeki Çakı Çapı, kullanılacak olan çakının çapının girilmesini sağlar.

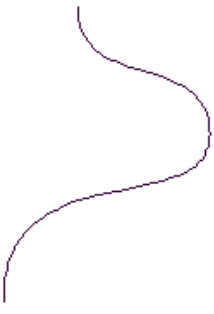

Serbest çizim

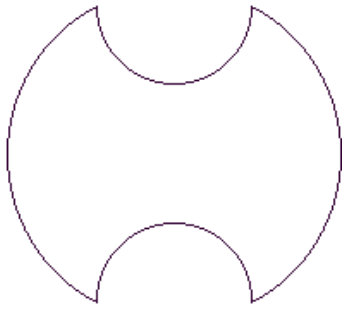

Kapalı çizim
Şekil 7. Çizim şekli 
Çalıştır menüsünde ve hızlı erişim araçlarından Başla seçeneği, iki boyutlu basılı bir çizimin üzerinden veya daha önce oluşturulmuş malzemenin etrafindan kablosuz kalem fare ile dolaştırılıp şekil oluşturma alanında çizilmesini sağlar. Başla seçeneği tıklandığında, şekil oluşturma alanında fare imleci sıfır (sol üst köşesi) konumuna yerleşir. Kablosuz kalem fare ikinci kez tıklanması ile kablosuz kalem farenin her piksel hareketinin X ve Y koordinatlarını oluşturup hem şekil oluşturma alanında senkron olarak çizimi oluştur hem de X ve Y koordinatları DataGridView nesnesine (koordinat listesi alanı) ekler. Kablosuz kalem fare çizim üzerinde dolaştırma işlemi tamamlandığında kablosuz kalem farenin sol tuşu tıklanarak oluşturma işlemi sonlandırılır. Kablosuz kalem fare ile Şekil oluşturma alanına eklenen PictureBox nesnesinin MouseMove olayına Şekil 10'da gösterilen metot uyguland. MouseMove olayı, farenin her konum hareketiyle tetiklenen olaydır. Böylece farenin hareketiyle bir önceki konum koordinatı ile o anki konum koordinatını bilgisi doğrultusunda vektörel çizim yapar. Çalıştır menüsünde ve hızlı erişim araçlarından Şekil Oluşturma, koordinat listesine girilen veya şekil oluşturma alanında bulunan şeklin koordinatları üzerinde yapılan değişiklikler doğrultusunda yeniden oluş̧urur. Çalıştır menüsünde ve hızlı erişim araçlarından Şekli Sil, şekil oluşturma alanını ve koordinat listesi penceresindeki verileri temizler. Şekil oluşturma alanındaki iki boyutlu çizimlerin koordinatları txt dosya tipi kullanılarak kaydetme/okuma işlemi yapılabilmektedir. Ayrıca oluşturulan çizimler bmp, png, jpeg, tiff, emf ve gif resim formatlarında dışa/içe aktarılmaktadır. Bu bmp, png, jpeg, tiff, emf ve gif uzantılı resim formatlarındaki iki boyutlu vektörel çizim çalışmaları içe aktarma işlemini Resim menüsü Resim Al seçeneği ile yapılmaktadır. İçe aktarılan resim formatlı çizimin vektörel çizime dönüştürülmesi Resim menüsü Resmi Çizime Dönüştür seçeneği uygulanarak yapılmaktadır. Bu işlem Resim Ayarı penceresi yapılabilir ve bu pencerede vektörel çizim ile yüklenen bitmap resim şekil oluşturma alanında gösterimi yapılmaktadır. Şekil 8'de görülen şekil oluşturma alanına yüklenen bitmap çizimin üzeri tıklandığı noktanın rengini (siyah) referans alarak seçili rengin bulunduğu pikselleri takip eder [24]. Tarama işleminin başından sonuna kadar çizimi oluşturan bütün tespit ettiği piksellerin $\mathrm{X}$ ve $\mathrm{Y}$ koordinat değerlerini Şekil 3'de gösterilen koordinat listesi alanındaki DataGridView nesnesine ekler. Böylece resim formatındaki iki boyutlu çizimin vektörel koordinatları elde edilmiş oldu. Bu iki boyutlu koordinatlar kullanılarak vektörel çizim elde edilir. Çalıştır menüsünde Şekli Düzelt seçeneği ile iki boyutlu vektörel çizimlerin üzerindeki dalgalanmalar düzeltilerek daha doğru bir çizim oluşturulur. Vektörel koordinatları bilinen iki boyutlu iş parçasının işleme derinliği ( $Z$ koordinatı) eklenerek CNC freze tezgahına Çalıştır menüsünde ve hızlı erişim araçlarından Tezgâha Aktar seçeneği gönderilir. İşleme Ayarı penceresindeki Şekil Taşıma seçeneği, oluşturulan şeklin malzemenin istenilen yerine işlenmesi için $\mathrm{X}, \mathrm{Y}$ ve $\mathrm{Z}$ belirtilen koordinatlara taşınmasını sağlar. İşleme Ayarı penceresindeki girilen ilerleme miktarı değeri ile oluşturulan şeklin bir seferde aldığı talaş derinliğini başka bir değişle paso değerini belirtilir. Aynı penceredeki İşleme Derinliği ile çakının Z eksen yönündeki ilerleme miktarı belirlenir. İşleme derinliği, işleme yeri, çakı çapı ve ilerleme hızı ayarları yapılan iş parçası, iş listesine eklenerek CNC freze tezgahına aktarmaya hazır duruma getirilir. Koordinat listesi penceresindeki koordinatlar ve belirtilen diğer işleme ayarları doğrultusunda Şekil 9'da tezgâha aktarma penceresinde son kontroller yapıldıktan sonra tezgâha aktarıp malzemeyi işlemesini sağlar. Ayrıca İçini Boşaltma Penceresi kısmında bir iş parçasının istenilen kısımlarında dikdörtgen, daire ve asimetrik geometrilerde içten dışa doğru malzemeyi işleyerek cep boşaltma işlemini yapmaktadır. Cep boşaltma işleminde $\mathrm{CNC}$ freze tezgahının kesme ucuna takılan çakının çapı baz alınarak dıştan içe doğru iş parçasından talaş kaldırarak işlemi gerçekleştirir (Şekil 11ab). Asimetrik cep boşaltma işleminde ise iş parçası üzerinde işlenecek geometrinin önce dış hattı sonra zig zag yaparak iç kısmını boşaltır (Şekil 11c).

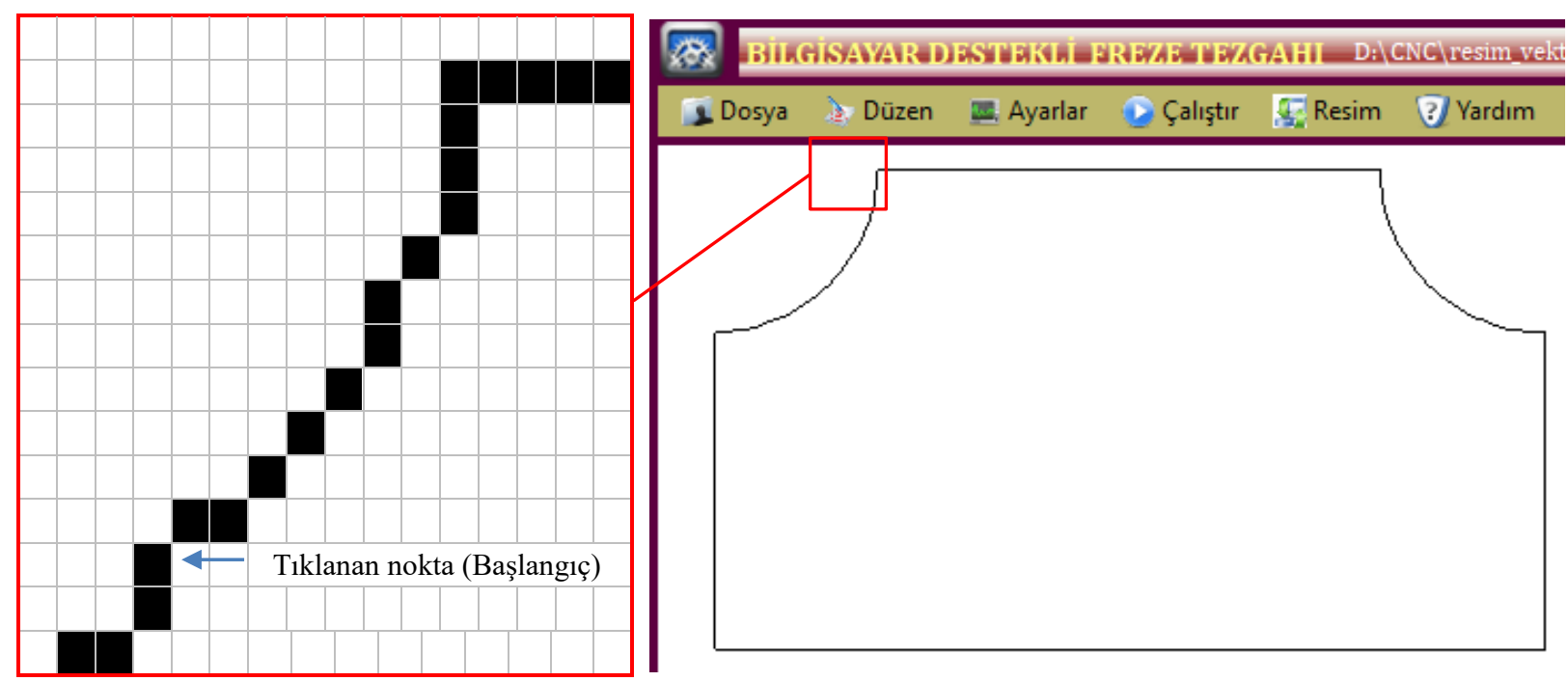

Şekil 8. İki boyutlu bitmap çizimi (sağ tarafta) ve çizimin piksel görünümü (sol taraf) 


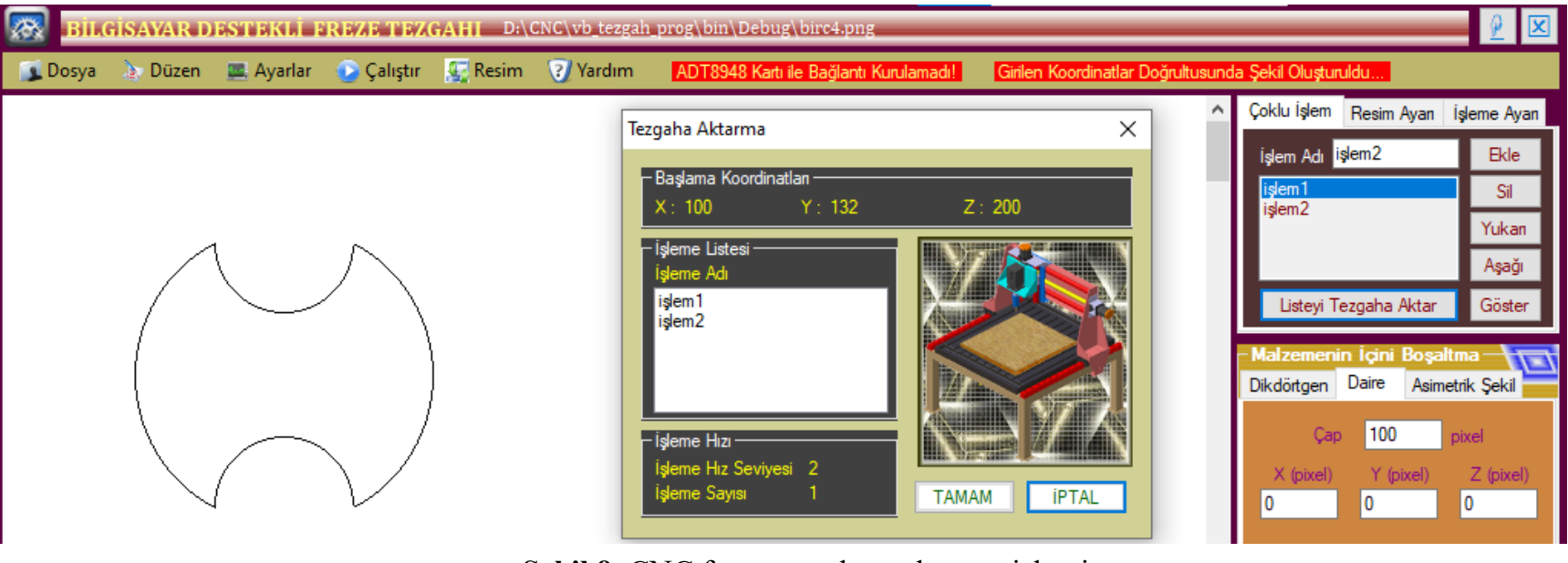

Şekil 9. CNC freze tezgahına aktarma işlemi

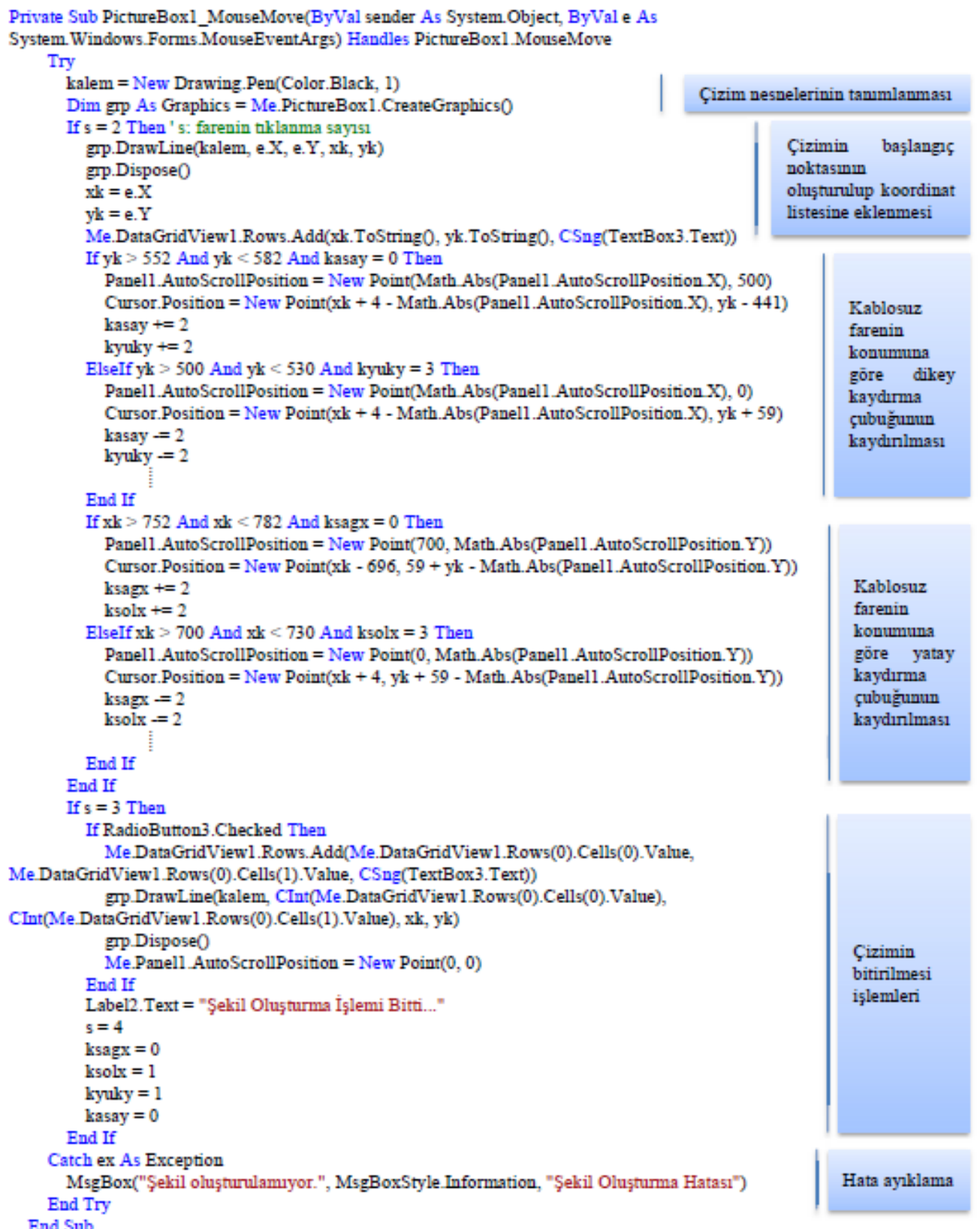

Şekil 10. Kablosuz kalem farenin hareketiyle çizimin oluşturulması 


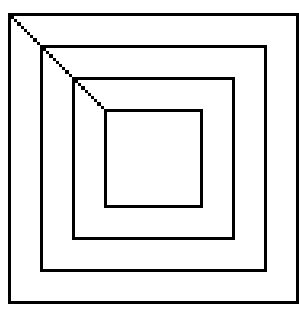

a)Dikdörtgen

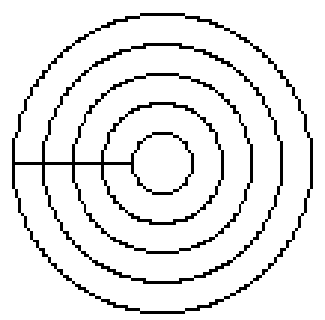

b)Daire

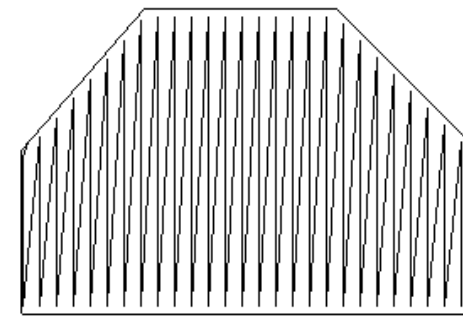

c)Asimetrik

Şekil 11. Cep boşaltma işlemi

\section{Sonuçlar}

Mobilya endüstrisinde kullanılan CNC freze tezgâhları için hazırlanan program arayüzü ile aşağıdaki işlemler başarıyla gerçekleştirdi.

- Ergonomik tasarımı sayesinde kullanıcıların CNC tezgahlarında kullanılan $G$ ve $M$ kodlarına ihtiyaç duymadan rahatlıkla kullanılabilen bir arayüz geliştirildi.

- Resim formatlarındaki iki boyutlu şekilleri başarılı bir şekilde vektörel çizime dönüştürerek takım yolları oluşturuldu.

- Dikdörtgen, daire ve asimetrik geometrilerde içten dişa doğru malzemeyi işleyerek cep boşaltma işlemi yapıldı.

- Şekil oluşturma alanındaki vektörel çizimler txt, bmp, png, jpeg, tiff, emf ve gif resim formatlarında kaydedildi.

- Program arayüzündeki başlık çubuğu, menü çubuğu, anlık durum göstergesi, şekil oluşturma alanı, hızlı erişim düğmeleri, koordinat listesi, cep boşaltma, işlem ayarı, çoklu işlem ve resim ayarı penceresi için hazırlanan metotlar doğru bir şekilde işlev yaptığı görüldü.

\section{Teşekkür}

$\mathrm{Bu}$ çalışma, Fırat Üniversitesi Bilimsel Araştırma Projeleri birimi tarafindan MF.11.19 no'lu proje kapsamında desteklenmiştir. Desteklerinden dolayı Fırat Üniversitesi Bilimsel Araştırma Projeleri birimine teşekkür ederiz.

\section{Çıkar çatışması}

Yazarlar çıkar çatışması olmadığını beyan etmektedir.

\section{Benzerlik oranı (iThenticate): $\% 8$}

Burada makalenin benzerlik oranı beyan edilmelidir.

\section{Kaynaklar}

[1] N. Hatem, Y. Yusof, A.Z.A. Kadir, K. Latif, M.M. Abedlhafd, Optimization and execution of multiple holes-drilling operations based on STEP-NC, Int. J. Adv. Manuf. Technol. 114 (2021) 2031-2043. https://doi.org/10.1007/s00170-021-06958-y.

[2] M. Mori, K. Yamazaki, M. Fujishima, J. Liu, N. Furukawa, A study on development of an open servo system for intelligent control of a CNC machine tool, CIRP Ann. - Manuf. Technol. 50 (2001) 247-250. https://doi.org/10.1016/S0007-8506(07)62115-5.

[3] Y. Zhang, Q. Zeng, G. Mu, Y. Yang, Y. Yan, W. Song,
Y. Gong, A design for a novel open, intelligent and integrated CNC system based on ISO 10303-238 and PMAC, Teh. Vjesn. 25 (2018) 470-478. https://doi.org/10.17559/TV-20170419111243.

[4] S. Bukofzer, N. Livesey, A framework for an intelligent CNC and data model, Int. J. Adv. Manuf. Technol. 19 (2002)727-735. https://doi.org/10.1007/ s001700200083.

[5] M. OLAM, Mobilya ve dekorasyon endüstrisinde kullanılacak bilgisayar destekli freze tezgâhının tasarımı, Firat university, 2012.

[6] G. Yan, H. Chen, X. Zhang, C. Qu, Z. Ju, A dimensiondriven adaptive programming for tool-path planning and post-processing in 5-axis form milling of hyperboloidal-type normal circular-arc gears, Int. J. Adv. Manuf. Technol. 106 (2020) 2735-2746. https://doi.org/10.1007/s00170-019-04723-w.

[7] X.B. Ma, Z.Y. Han, Y.Z. Wang, H.Y. Fu, Development of a PC-based open architecture software-CNC system, Chinese J. Aeronaut. 20 (2007) 272-281. https://doi.org/10.1016/S1000-9361(07)60044-2.

[8] B.C. Kim, I. Song, D. Mun, Practical method for the fast generation of a CAM model for jet engine parts, Adv. Mech. Eng. 13 (2021). https://doi.org/ $10.1177 / 16878140211002700$

[9] L.M. Xu, F. Fan, Z. Zhang, Y. Chen, D.J. Hu, L. Shi, Methodology and implementation of a vision-oriented open CNC system for profile grinding, Int. J. Adv. Manuf. Technol. 100 (2019) 2123-2131. https://doi.org/10.1007/s00170-018-2843-7.

[10] C. Faria, J. Fonseca, E. Bicho, FIBR3DEmul-an open-access simulation solution for 3D printing processes of FDM machines with 3+ actuated axes, Int. J. Adv. Manuf. Technol. 106 (2020) 3609-3623. https://doi.org/10.1007/s00170-019-04713-y.

[11] F.Q. Qi, X.D. Jing, K. He, Control system of stepper motor based on roundness and cylindricity measuring virtual instrument, in: Procedia Eng., Elsevier, 2011: pp. 2281-2285. https://doi.org/10.1016/j.proeng. 2011.08.427.

[12] D. Chang, A.D. Spence, S. Bigg, J. Heslip, J. Peterson, Open architecture CMM motion controller, in: Sensors Control. Intell. Manuf. II, SPIE, 2001: pp. 1-9. https://doi.org/10.1117/12.452646. 
[13] F. Lustig, J. Dvorak, P. Kuriscak, P. Brom, Open modular hardware and software kit for creations of remote experiments accessible from $\mathrm{pc}$ and mobile devices, Int. J. Online Eng. 12 (2016) 30-36. https://doi.org/10.3991/ijoe.v12i07.5833.

[14] W. Bolton, Control Systems, in: Instrum. Control Syst., Elsevier, 2021: pp. 297-328. https://doi.org/10.1016/ B978-0-12-823471-6.00013-7.

[15] S.L. Harris, D.M. Harris, I/O Systems, in: Digit. Des. Comput. Archit., Elsevier, 2016: pp. 531.e1-531.e64. https://doi.org/10.1016/b978-0-12-800056-4.00015-7.

[16] G. Lee, Server Virtualization and Networking, in: Cloud Netw., Elsevier, 2014: pp. 103-120. https://doi.org/10.1016/b978-0-12-800728-0.00006-0.

[17] The System Bottleneck Shifts To PCI-Express, (n.d.). https://www.nextplatform.com/2017/07/14/systembottleneck-shifts-pci-express/ (accessed May 19, 2021).

[18] Centralized Motion Control - Advantech, (n.d.). https://www.advantech.eu/products/centralizedmotion-control/sub_b17a0020-bf63-42e9-af531c8c533e45e3 (Accessed May 20, 2021).

[19] Motion Control Cards (Control In Motion), (n.d.). https://www.controlinmotion.com/products/motioncontrol/motion-control-cards/index.shtml (Accessed May 20, 2021).

[20] J. Đurković, V. Vuković, L. Raković, Open Source Approach in Software Development-Advantages and Disadvantages, Manag. Inf. Syst. 3 (2008) 29-033. http://www.ef.uns.ac.rs/mis/archive-pdf/2008 No2/MIS2008_2_5.pdf.

[21] M.J. Heron, V.L. Hanson, I. Ricketts, Open Source and Accessibility: Advantages and Limitations, J. Interact. Sci. 1 (2013) 2._https://doi.org/10.1186/2194-0827-1-2.

[22] Newfangled Solutions CNC Software Home of Mach3, (n.d.). https://www.machsupport.com/ (Accessed May 20, 2021).

[23] Software for download | HEIDENHAIN, (n.d.). https://www.heidenhain.com/service/downloads/softw are (Accessed May 20, 2021).

[24] M. Olam, I. Hakk1, N. Tosun, Converting a pixel graphic into toolpath for machining on a CNC milling machine, in: Institute of Research Engineers and Doctors, LLC, 2016: pp. 59-61. https://doi.org/ 10.15224/978-1-63248-099-6-38. 